\title{
Livro didático e letramento crítico: um diálogo possível?
}

\author{
Textbooks and critical literacy: can they dialogue?
}

\author{
Jhuliane Evelyn da SILVA* \\ Universidade Federal do Paraná (UFPR)
}

RESUMO: Dada a escassa formação em nível acadêmico voltada à Educação de Jovens e Adultos (EJA), bem como a relevância do ensino-aprendizagem de línguas para este público, intentamos ofertar uma leitura de livros didáticos observando suas potencialidades, bem como maneiras de utilizá-los em ambiente educacional. Faremos isto fundamentados no letramento crítico em um viés pós-estruturalista, considerando seus pressupostos filosóficos e os construtos de língua, de papel do professor e do aluno e da função da educação para esta abordagem. Nesse sentido, analisaremos o livro Caminhar e transformar (2013) e a coleção EJA Moderna (2013), materiais aprovados pelo PNLD EJA 2014-2016 para esta modalidade, séries finais do ensino fundamental. A análise indica a possibilidade de uso produtivo do material a partir de um movimento de localização e ressignificação do conteúdo que considera as realidades dos alunos, além de elucidar a agência do professor para manejar os recursos ofertados pelo material.

PALAVRAS-CHAVE: Letramento crítico. Livro didático. EJA. Formação crítica.

\begin{abstract}
Given the relevance of teaching and learning languages to youth and adult education (EJA) as well as the low number of teacher education specific to this audience, we intend to offer a reading of two textbooks observing their potentialities and ways to use them in an educational environment. Based on the theoretical framework of critical literacy in a poststructuralist perspective, we will consider its understandings on reality, knowledge, language, role of teacher and student and function of education. In that sense, we will use the textbook Caminhar e Transformar (2013), and the EJA Moderna series (2013), materials approved by the Brazilian textbook program (PNLD) for EJA (2014-2016), final series of elementary school. The analysis
\end{abstract}

\footnotetext{
* Mestre em Linguagem e Ensino pela Universidade Federal de Campina Grande (UFCG). Doutoranda em Letras pela Universidade Federal do Paraná (UFPR), Setor de Ciências Humanas, Curitiba-PR. Contato: anecomjesus@gmail.com
} 
indicates the possibility of their productive use when teachers and students localize and re-signify the content to consider the realities lived, as well as stresses the teacher's agency when managing resources offered by the textbooks.

KEYWORDS: Critical literacy. Textbook. Youth and adult education. Critical education.

\section{Introdução}

De objetivos que vão desde o crescimento "[d]o contingente eleitoral”, "critério de ascensão social”, “compensação pelos princípios de reparação e equidade” até o entendimento atual de "direito" em si (PARANÁ, 2006), percebemos que a trajetória da Educação de Jovens e Adultos (doravante EJA) caracteriza-se por ser deveras complexa e atravessada por percalços de toda sorte, principalmente políticos.

Consoante as Diretrizes Curriculares Estaduais (DCE) do Estado do Paraná, historicamente, no Brasil, temos uma oferta de educação extremamente excludente, na qual alguns sujeitos têm preferência em detrimento de outros, sejam homens sobre mulheres, brancos sobre negros, ricos sobre pobres, cristãos sobre não-cristãos, entre outras. Em virtude desta realidade, "é muito recente a conquista, o reconhecimento e a definiç̧ão desta modalidade como política pública de acesso e continuidade à escolarização básica.” (PARANÁ, 2006, p. 16).

A EJA como hoje se apresenta é fruto dos encaminhamentos da Constituição Federal de 1988 que a reconheceu enquanto modalidade constituinte da Educação Básica com características próprias (apesar de não ser financiada por fundo destinado a esse contingente) e consequentemente da Lei de Diretrizes e Bases da Educação Nacional (LDB, $n^{\circ}$ 9.394/96), que em seu artigo 4, inciso 7 estabelece que haja “oferta de educação escolar regular para jovens e adultos, com características e modalidades adequadas às suas necessidades e disponibilidades, garantindo-se aos que forem trabalhadores as condições de acesso e permanência na escola”. (BRASIL, 2010, p. 8-9).

Apesar de tantos passos percorridos, diversos estudos apontam que à modalidade de Educação de Jovens e Adultos pouca atenção é dada seja em contexto de formação 
docente para este público seja em contexto de atuação profissional (ARAÚJO; AMORIM; DANTAS, 2016, FREITAS; RIBEIRO, 2014, SILVA, 2011). Considerando que quem ${ }^{1}$ volta aos bancos das salas de aula geralmente são jovens cuja faixa etária não mais os permite cursar a modalidade regular e adultos e idosos que por quaisquer motivos tiveram de desistir, que visam ao preparo para o mercado de trabalho e à ascensão social, não se pode vislumbrar qualquer tipo de educação que se queira problematizadora e transformadora, voltada ao social, que relegue o contexto singular de realidades específicas com as quais devemos aprender.

Por esta razão, pensamos que a educação como um todo, bem como a EJA e o ensino de língua inglesa mais especificamente, deve ser problematizada por meio de um viés crítico (BOHN, 2013). Assim, ao nos engajarmos em um letramento crítico redefinido (LC), defendemos uma prática problematizadora que busque possibilidades contingentes de ação e que nunca perca de vista o caráter ético de nossas ações dentro e fora da sala de aula (MENEZES DE SOUZA, 2011a, JORDÃO, 2013a, 2014, FOGAÇA et al, 2017, PENNYCOOK, 2004). A proposta desta prática problematizadora está fincada nas práticas docentes cotidianas como um exercício de eterno becoming (uma espécie de tornar-se constante, que nunca chega em um ponto, mas que vive em movimento): becoming professor, becoming aluno, becoming cidadãos, becoming agentes de criticidade (DELEUZE; GUATTARI, 1995). Pensamos, a partir disso, que professores desta modalidade devem buscar desenvolver uma práxis pedagógica que os possibilite uma atuação mais condizente com as realidades que eles encontram em suas salas de aula e que não raro os desestimulam.

Decorre disso a importância do material didático adotado na escola e que na maioria do tempo materializa currículos e diretrizes e guia os professores em suas rotinas de trabalho. Tendo em vista o quase monopólio do livro didático em relação a outros materiais educativos, objetivamos neste texto ofertar uma leitura do material observando suas potencialidades, bem como maneiras de utilizá-lo em ambiente educacional de modo a realizar um trabalho mais responsivo às necessidades desses sujeitos, que possuem culturas,

\footnotetext{
${ }^{1}$ Este público aumentou significativamente após a redução da idade mínima para certificação pela conclusão do Ensino Fundamental e Médio de 18 e 21 anos para 15 e 18 anos, respectivamente. (PARANÁ, 2006).
} 
tempos e intenções distintas. Isso tudo a partir de uma proposta didática à luz do letramento crítico em um viés pós-estruturalista, considerando os construtos de língua, de conhecimento, de papel do professor e do aluno e de função da educação.

Para tanto, observaremos os livros de inglês pertencentes às coleções Caminhar e transformar (2013), utilizada de 2014 até 2017, e EJA Moderna (2013) que passou a ser utilizado nas escolas em 2018, ambos materiais aprovados pelo Programa Nacional do Livro Didático (PNLD EJA 2014-2016²) para a modalidade EJA, séries finais do ensino fundamental. Estes livros foram escolhidos tendo em vista a participação da pesquisadora em uma pesquisa colaborativa ${ }^{3}$ em cujo contexto esses materiais estavam disponíveis a todos os professores desta modalidade.

Assim, o artigo está dividido nesta Introdução e em outras três seções. Na primeira, buscamos localizar o livro didático em meio a críticas quanto à sua adoção em sala de aula; na segunda, descrevemos brevemente o letramento crítico como uma proposta localizada e reflexiva que, por seus pressupostos, parece-nos responder produtivamente às especificidades da modalidade; e na terceira, lemos as coleções de modo a ver possibilidades de trabalhar o LC a partir dos livros que estão presentes e disponibilizados nas escolas públicas, isto é, a partir do que se tem.

\section{O livro didático}

O livro didático, dentre tantos materiais didáticos possíveis de serem trabalhados em sala, vem sendo amplamente estudado pela Linguística Aplicada e pela Educação por ser o instrumento pedagógico mais presente dentro das salas de aula de língua estrangeira (HOLDEN; ROGERS, 2002) e que, portanto, acaba por exercer grande influência sobre o processo de ensino-aprendizagem daquela. O enfoque a ele atribuído em detrimento dos demais se dá em virtude tanto de sua ampla utilização em sala de aula quanto pelo comércio altamente lucrativo do mercado editorial (VILAÇA, 2009, KUMARAVADIVELU, 2012). Duas das consequências desse grande espaço concedido a ele acriticamente pode ser sua

\footnotetext{
${ }^{2}$ Única edição até então deste programa voltada à EJA.

${ }^{3}$ Pesquisa de doutoramento em andamento (2017-2021).
} 
contribuição para a propagação de ideologias dominantes vigentes (CORACINI, 1999), bem como a não consideração da agência, capacidade e experiência do professor em sua prática docente cotidiana.

O material didático pode ser entendido como "qualquer coisa empregada por professores e alunos para facilitar a aprendizagem" (SALAS, 2004, p. 2). Essa definição, ainda que vaga, abre portas à interpretação que qualquer material, seja livro, caderno de atividades, CD-ROM, CD, DVD, vídeos, aplicativos, podcasts, ou outro que esteja voltado ao processo de ensino (que auxilie o professor) e aprendizagem (que assista o aluno lhe ofertando maior possibilidade de produção de conhecimento) poderá ser considerado como didático, pois exerce função primordialmente pedagógica.

Cunningsworth (1995) aponta outras funções, dentre as quais se podem destacar o livro didático como um recurso para a apresentação de conteúdo, para a prática de atividades para a apreensão do assunto, para o favorecimento de uma aprendizagem autodirecionada, bem como um suporte para os professores que precisam adquirir confiança, uma vez que o livro utilizado por ele oferece

[...] uma previsibilidade que é necessária a fim de que o evento social se torne tolerável aos participantes, além de servir de mapa ou plano para o que se pretende e o que se espera, permitindo, assim, que os participantes vejam onde uma lição se encaixa dentro de um contexto mais amplo do programa linguístico. (CRAWFORD, 2002, p. 83).

Desse modo, como defende Crawford (2002), a escolha da utilização do livro didático pelo professor se justifica pela previsibilidade ofertada a esses profissionais, que obtém do livro um plano que os direciona quanto à metodologia e ao conteúdo que deve ser ensinado em sala de aula. Allwright (1981), por sua vez, propõe que a razão pode ser a dificuldade enfrentada por alguns professores no preparo e na seleção do seu próprio material didático. Huctchinson e Torres (1994) discordam dessa visão ao alegarem que o real motivo desta escolha é a conveniência proporcionada pelo livro, haja vista ser ele uma ferramenta que fornece a estruturação exigida pelo sistema de ensino.

Concordamos que a comodidade oferecida pela previsibilidade do material didático é necessária, pois auxilia o professor na condução de suas aulas em meio a tantas 
atribuições que assume na escola e a descasos recorrentes na profissão (falta de tempo, de formação continuada, de remuneração adequada). Mas, como supracitado, o material deve funcionar como auxiliador, não como condutor da aula, modo como alguns professores, em vista da carência de uma formação crítica, acabam por utilizá-lo: como um guia que deve ser seguido progressivamente, sem adaptações ou adequações contextuais. Salas (2004) confirma essa visão ao constatar que o material se constitui muitas vezes como o programa de ensino das disciplinas, havendo uma valoração exacerbada em relação àquele. Aqui o professor não enxerga que possui diferentes sujeitos e expectativas para atender, não se abre para discutir a necessidade do aluno, tampouco adequa esse material à realidade vivida pelo mesmo.

É justamente esta prática que revela as limitações do livro didático. No ato da escolha do material a ser utilizado em sala de aula, o professor busca seus interesses, o que entende como relevante, os temas que o livro deve abordar e que devem ser trabalhados. Porém, a escolha dos materiais não é algo simples. Deve estar baseada no aluno que será seu usuário (seus anseios, expectativas e gostos pessoais) e no contexto local de ensino (instituição, localização, comunidade, faixa etária) (LEFFA, 2003).

Ademais, há que se considerar a questão da adequação ao contexto no qual os sujeitos - professores e alunos - se fazem presentes, uma vez que o livro (principalmente o de línguas estrangeiras) tende a transmitir acriticamente as ideologias de determinados grupos dominantes através de textos multimodais, favorecendo a alienação sobre a língua, a cultura e o modo de viver do outro. Destarte, a análise do livro didático não pode ser relegada, visto a sua grande influência e relevância no processo de ensino-aprendizagem, mais especificamente na condução das aulas de línguas. Neste artigo, sublinhamos que nossas atitudes em sala de aula a partir do manuseio, adequação e ressignificação do livro estavam assentadas no que entendemos que seria letramento crítico redefinido, abordagem que trataremos a seguir.

\section{O letramento crítico}


Para tratarmos do letramento crítico, deter-nos-emos em pressupostos ontológicos e epistemológicos discutidos por estudiosos pós-estruturalistas e nos entendimentos sobre língua, papel assumido pelos sujeitos professor e aluno e função da educação decorrentes desses pressupostos, com vistas a compreendermos o porquê de sua escolha para o trabalho produtivo da língua inglesa em sala de aula da Educação Básica, em especial da modalidade EJA.

Compreendemos a realidade (ontologia) enquanto "inacessível a nós sem a linguagem" (FOGAÇA et al, 2017, p. 188), não podendo, portanto, ser apreendida completamente como algo que é, que está lá, fora da influência dos sujeitos. Por esta razão, nossas perspectivas de realidade são sempre da ordem da interpretação. Isso implica dizer que olhamos o mundo e vivenciamos a "realidade" por meio do nosso olhar, que é sempre ideológico: "perspectiva cultural, social, moral que nos permite entender as coisas do jeito como as entendemos" (JORDÃO, 2013b, p. 41, ênfase no original). Por conseguinte, de acordo com os pressupostos pós-estruturalistas sobre os quais o LC se fundamenta, não há uma realidade fora do texto, pré-existente ao sujeito e à língua, haja vista nossos entendimentos de mundo serem sempre frutos de nossas interpretações - construções sociais validadas pelas comunidades interpretativas das quais fazemos parte. (JORDÃO, 2010).

Nesta mesma perspectiva, o conhecimento (epistemologia) se constitui como uma construção que é sempre ideológica, situada, incompleta, diversa, "é saber sempre passível de contestação e questionamento" (JORDÃO, 2013b, p. 45). Este entendimento de conhecimento, de acordo com a autora, se assemelha ao conceito de discurso para Foucault. Nesse sentido, não há algo que se possa ser considerado uma verdade absoluta; o que há são verdades no plural, algumas com mais privilégio e poder do que outras a depender do poder das comunidades interpretativas que as validam em determinado tempo e espaço. São, portanto, mutáveis. Como Menezes de Souza nos alerta (2011a, p. 136), "cada produção de significação de cada comunidade adquire sua validade apenas em dado momento histórico desta comunidade". Para o LC, então, esse entendimento se faz necessário para que em uma leitura crítica possamos 
(1) perceber não apenas como o autor produziu determinados significados que tem origem em seu contexto e seu pertencimento sócio-histórico, mas ao mesmo tempo, (2) perceber como, enquanto leitores, a nossa percepção desses significados e de seu contexto sócio-histórico está inseparável de nosso próprio contexto sócio-histórico e os significados que dele adquirimos. (MENEZES DE SOUZA, 2011a, p. 132, ênfase no original).

Por conseguinte, a multiplicidade de sentidos advinda das diversas ideologias reconhecidas é vista como produtiva, uma vez que interpretações e verdades são construtos partilhados socialmente. Vistos sob esse viés, o professor tem a responsabilidade, dentro de seu contexto, de trabalhar com esses diferentes discursos, verdades ou representações de modo positivo, além de ensinar seu alunado a construir novos sentidos partindo de tudo o que lhe é apresentado dentro e fora da sala de aula (JORDÃO, 2013a).

O LC oferta noções de língua, papéis do professor e do aluno e ainda a função da educação de forma ressignificada para responder mais produtivamente aos pressupostos supramencionados. Deste modo, assentamo-nos em Jordão (2013a) para trazer à luz o conceito de língua. Buscando respaldo em vários autores (sobretudo pós-estruturalistas), esta estudiosa concebe a língua como "um espaço ideológico de construção e atribuição de sentidos que se dá num processo enunciativo sempre contingente (relativo a sujeito, tempo e espaço específicos) numa prática situada de letramento". (JORDÃO, 2013a, p. 74). O entendimento da língua como discurso nos permite assumir o processo de ensinar línguas como sendo criativo, não estanque ou fixado em sentidos pré-estabelecidos. Logo, torna-se possível ver a docência enquanto um espaço para a criação de novos sentidos, novos modos de representar, perceber e reinventar a si mesmo, o outro e o mundo que sejam sensíveis aos contextos locais e globais nos quais nos localizamos. (FOGAÇA et al, 2017).

Como uma prática social, depreendemos que a língua também é cultural, heterogênea, plural, política, situada e global, levando-nos à compreensão do nosso papel ativo na sociedade. Se tomarmos a sala de aula como espaço privilegiado para a construção e negociação de significação, podemos configurá-la como lócus para atribuição de sentidos ao mundo, uma vez que, principalmente na sala de aula de língua estrangeira, vemos diferentes e novas formas de apreender e respeitar o mundo, outras culturas e outras vivências. 
Ambos professores e alunos são considerados como construtores, produtores de significação, portanto, agentes de criticidade, interpretadores de suas realidades. Ao professor, mais especificamente, é dada a função de criar contingências e espaços para que a aprendizagem aconteça, de modo a fomentar o posicionamento crítico diante do mundo e a "aprender e ensinar procedimentos de construção de sentidos" (FOGAÇA et al, 2017, p. 192, ênfase no original). Do aprendiz é esperada participação ativa ${ }^{4}$ na construção de sentidos e implicação em seu próprio processo formativo. A partir desses papéis, a transformação almejada pelo LC é aquela que modifica o nosso modo de ler o mundo e a nós mesmos, que nos permite entender a multiplicidade de sentidos de forma positiva e o dissenso de forma produtiva.

Em virtude da discussão ora posta é que entendemos que a educação, no LC, assume por função a problematização das práticas de construção de sentidos (JORDÃO, 2013a), tendo em vista que a forma como os saberes e conhecimentos são produzidos e circulam atualmente sinaliza para uma possível e desejada reconfiguração do espaço da sala de aula, muitas vezes visto como local privilegiado para a "transmissão" de conhecimento. A função da educação e da escola estaria em fornecer esses espaços de diálogo com vistas à transformação social, isto é, um espaço de conscientização do outro e de si (JORDÃO, 2010), cujo foco esteja no diálogo produtivo com a diferença (MENEZES DE SOUZA, 2011a).

Em relação à sala de aula de línguas, tomamos Menezes de Souza (2011a) e seu conceito de genealogia como um dos objetivos do ensino-aprendizagem de língua inglesa: devemos buscar um processo de ler se lendo, de questionar e reconhecer as produções textuais anteriores das quais nós fizemos parte direta e/ou indiretamente, tudo isso por perceber que nossas histórias são sempre coletivas e sócio-históricas, validadas em determinado momento histórico das comunidades interpretativas das quais nós participamos (MENEZES DE SOUZA, 2011a). Esta atitude do ler se lendo ressoa na reflexividade postulada pelas teorias pós-estruturalistas, que nos permitem entender que

\footnotetext{
${ }^{4}$ Por agente e ativo não queremos nos referir a um sujeito cognoscente, autônomo e livre, mas sim, a um sujeito que é sempre social e que está situado em um determinado contexto que o impele a fazer coisas e a tomar decisões sobre o mundo de certas formas.
} 
este também é um discurso e que, como tal, deve ser entendido em sua parcialidade e contingência.

Diante dos construtos mencionados neste texto, assumimos o letramento crítico ${ }^{5}$ de viés pós-estruturalista, ou redefinido, "como uma referência para o desenvolvimento de práticas locais" (FOGAÇA et al, 2017, p. 191). O termo redefinido ressalta a complexidade constitutiva do mundo e dos seres, a provisoriedade dos sentidos e das soluções que ofertamos aos problemas, a reflexividade que deve ser central neste modo de ler o mundo e a si mesmo e a necessidade de aprender a escutar os muitos outros que nos habitam e que habitam o Outro.

Em sala de aula, portanto, deveremos adotar uma postura sempre de suspeita dos textos (em seu sentido amplo - mundo, palavra e o eu), de maneira a questionar sobre o contexto político, histórico, ideológico no qual determinado texto foi produzido, o seu público-alvo, as diferentes leituras que podem ser produzidas a depender do contexto (de produção e de recepção do texto), os sentimentos dos leitores com relação aos sentidos construídos e os almejados, entre outras. (MENEZES DE SOUZA, 2011b).

Nós, professores, geralmente temos dificuldade em lidar com a diversidade e com o conflito que certamente esse tipo de prática abrirá vazão. Contudo, não podemos ter a pretensão de controlar o conhecimento ou o processo de construção deste nos alunos. Precisamos buscar soluções reconhecidamente locais e provisórias para quaisquer situações que se nos apresentem, sem ter a pretensão de resolver tudo. Ou seja, devemos perceber e mostrar ao aluno a inutilidade em querer se impor sobre o outro, em querer silenciá-lo.

A alternativa proposta pelo LC, enquanto postura problematizadora, nos indica que devemos buscar possibilidades contingentes, distintas, localizadas e ambivalentes para cada situação que se coloca. Como nos diz Pennycook (2004), ser crítico é um processo contínuo que se dá em uma base diária a partir do que temos disponível, do que é possível fazer naquele momento e muitas vezes da impossibilidade de se fazer algo. Daí a importância da

\footnotetext{
${ }^{5}$ Segundo Duboc e Ferraz (2018, p. 240), os estudos mais recentes nos letramentos críticos têm demonstrado a expansão na noção de crítica, a emergência de um outro tipo de questionamento que entende os sujeitos leitor e autor como tendo identidades fluidas e provisórias e a agência situada em práticas de cunho mais localizado. Em virtude desses encaminhamentos, adoto neste texto o entendimento de letramento crítico redefinido, discutido principalmente por autores brasileiros, como Menezes de Souza $(2011,2017)$ e Jordão (2013, 2014).
} 
colaboração: ao sairmos do papel de transmissores e detentores do conhecimento, assumimos nossa incompletude e abrimos espaço para novos entendimentos, novas alternativas e novas práticas que sejam sensíveis e mais adequadas aos problemas que se nos apresentam regularmente (FOGAÇA et al, 2017, TICKS; SILVA; BRUM, 2013). Ademais, por envolver a ação conjunta entre professores, alunos, pesquisadores e coordenadores, a colaboração se mostra fulcral para o processo de formação de professores tanto inicial - no trabalho significativo a partir da prática - quanto contínua - no trabalho e pesquisa com seus pares (MILLER, 2013).

\section{O livro didático sob o olhar do letramento crítico}

Apesar das críticas levantadas ao livro didático (LD) no início deste texto, não precisamos rejeitá-lo e tampouco devemos negar sua importância para a prática docente, principalmente se levarmos em consideração o contexto de sala de aula, o tempo e as condições de trabalho do professor de línguas, especificamente. Por isso, um passo para a sua utilização é refletir colaborativamente - com outros professores e com os alunos - sobre as propostas do LD (FOGAÇA et al., 2017, JORDÃO, 2014). Menezes de Souza (2011b) nos aconselha a, enquanto professores, olhá-lo criticamente, sem receio de subverter suas indicações de prática:

O que eu quero dizer é que há várias maneiras de usar livros: eles não precisam ser usados simplesmente seguindo a ordem numérica ou linear; podemos começar de acordo com o interesse dos nossos alunos, a atividade que queremos, podemos começar na página 10 antes da página 3. (MENEZES DE SOUZA, 2011b, p. 281).

Para promover a reflexividade em sala de aula, Pennycook (2004) nos incentiva a buscar momentos críticos, ou seja, momentos pequenos, diários e, muitas vezes, nãoplanejados de mudança potencial com vistas a promover no professor e em seus alunos a "integração reflexiva contínua" da práxis (PENNYCOOK, 2004, p. 334). Isto pode ser feito também a partir de uma prática docente mais situada, que busque no livro momentos 
potenciais de crítica ao problematizar os conceitos sendo trabalhados, os diálogos sendo repetidos e as estruturas sendo memorizadas.

Outro autor que trata da utilização do LD em sala de aula é Kumaravadivelu (2012). Ele assume em sua pesquisa a necessidade de combatermos a violência epistêmica do Norte global, principalmente por serem os países responsáveis pela produção e venda dos livros para ensino de língua estrangeira, geralmente consumidos por nós, países que têm a LI oficialmente como segunda língua ou língua estrangeira. Em decorrência disso, sugere a formação de professores enquanto um espaço para análise e produção de seu próprio material.

Para falar de ressignificação de material didático, localizamos nossa prática docente no ensino de inglês na modalidade EJA de nível fundamental e médio. Consoante as DCE da educação de jovens e adultos do estado do Paraná, a EJA deve ser reconhecida como uma "política pública de acesso e continuidade à escolarização básica" (PARANÁ, 2006, p.16) e não mais como uma compensação, como era vista outrora. Ela tem como finalidades e objetivos "o compromisso com a formação humana e com o acesso à cultura geral, de modo que os educandos aprimorem sua consciência crítica e adotem atitudes éticas e compromisso político, para o desenvolvimento da sua autonomia intelectual" (PARANÁ, 2006, p. 27).

Como descrito na Introdução, esta modalidade atende um público composto por jovens, adultos e idosos, sujeitos vistos como "sujeitos de conhecimento e aprendizagem, de sua história e condição socioeconômica, sua posição nas relações de poder, sua diversidade étnico-racial, territorial, geracional e cultural, dentre outras" (PARANÁ, 2006, p. 16).

Ademais, a EJA possui como eixos articuladores a cultura, o trabalho e o tempo, o que implica na necessidade de considerar os saberes adquiridos ao longo da vida desses aprendizes, que sabem o motivo de estar ali. Esses eixos norteiam os conteúdos do currículo escolar para essa modalidade de modo a manter as características de organização próprias da EJA, quais sejam: 1) possibilitar aos educandos "trajetórias de aprendizagem não-padronizadas" de maneira a respeitar o tempo de aprendizagem de cada um; e 2) 
“organizar o tempo escolar a partir do tempo disponível do educando-trabalhador". (PARANÁ, 2006, p. 25).

Este contexto nos levou a pensar a EJA a partir das especificidades locais, considerando o tempo de cada aluno, a escola, os conteúdos a serem trabalhados, o material disponível apenas para o Ensino Fundamental ${ }^{6}$, mas que serve para o Ensino Médio também, e ainda a não obrigatoriedade das avaliações formais. Ou seja, entendemos a EJA enquanto um momento e espaço privilegiado para a proposta do LC redefinido. Por isto, buscamos apresentar a seguir como utilizamos produtivamente o material fornecido pela escola.

Tendo como base os conteúdos do Ensino Fundamental e a necessidade de revisão e aprofundamento dos mesmos para o nível médio, pensamos ${ }^{7} \mathrm{em}$ temas que norteassem nossas ações em sala de aula. Eles foram 1) Identidade, pluralidade e trabalho, 2) Direitos humanos, 3) Moradia, saúde e qualidade de vida e 4) Desenvolvimento e sustentabilidade. Esses temas perpassam todos os livros da EJA de editoras distintas e em quaisquer disciplinas, como podemos observar a partir dos sumários dessas coleções ${ }^{8}$. Para este artigo, a título de exemplo, debruçar-nos-emos sobre a unidade 4, - My life, our world, que faz parte do segundo tema escolhido e que trata de cidadania e de direitos humanos, do livro Caminhar e transformar (Inglês), bem como sobre o capítulo 3 da unidade 2 - A sociedade Brasileira da coleção EJA Moderna ( $8^{\circ}$ ano) que trata da cidadania, pois o trabalho em sala de aula foi realizado com os dois (e outros que aqui não foram listados, mas que foram disponibilizados pela escola independentemente dos anos de publicação).

Para trabalhar o tema, utilizamos o livro como material didático disponível, e, por isso, não nos detivemos a ele nem à disposição e progressão de suas páginas. Como trataríamos de direitos humanos, observamos nos livros a presença de ativistas como

\footnotetext{
${ }^{6}$ Ainda não há até o momento desta publicação livros específicos e aprovados pelo PNLD de distribuição gratuita para a EJA nível médio.

${ }^{7}$ Colaboração empreendida em sala de aula de EJA, aprovada sob o parecer CEP/SD-PB n ${ }^{0}$ 2.993.546.

${ }^{8}$ Por questões de espaço, descreveremos pontualmente os temas tratados em cada coleção. Caminhar e transformar (todos os anos finais do EF): Identidade e diversidade, Meio ambiente e sustentabilidade, O mundo do trabalho e Cidadania e direitos humanos. EJA Moderna $-6^{\circ}$ ano: Identidade e pluralidade e Alimentação. $7^{\circ}$ ano: Moradia e Saúde e qualidade de vida. $8^{\circ}$ ano: O país e A sociedade brasileira. $9^{\circ}$ ano: Trabalho e Desenvolvimento e sustentabilidade. Na coleção EJA moderna, esses temas se repetem nas distintas disciplinas.
} 
Gandhi, Mandela, Martin Luther King, Jr. e Rosa Parks e decidimos centrar nossas atividades de discussão, tradução e gramática em torno deles, de seus discursos, pensamentos e biografias, bem como nas imagens e textos disponibilizados nos livros. (Figura 1).

Figura 1: Imagens das unidades
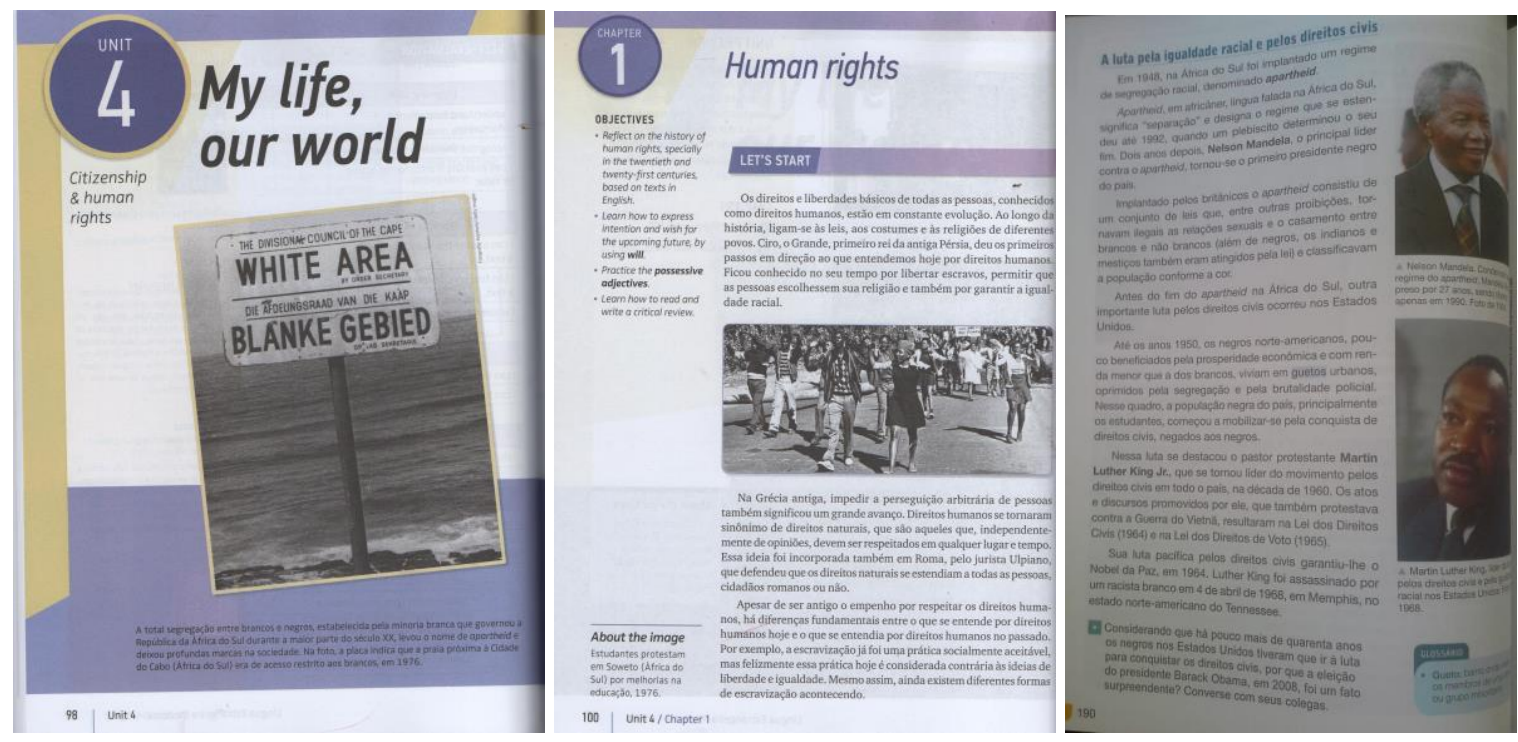

Fonte: Aarão e Zatti (2013, p. 98 e p. 100) e EJA Moderna (2013, p. 190)

Como mostrado na Figura 1, além das placas sobre a segregação racial, há um pequeno texto em língua portuguesa falando sobre os direitos de todos e todas, que problematiza todas as formas de discriminação e de privações que tantos ainda sofrem. Entendemos que este tema seria de grande importância para os alunos pois eles mesmos se enquadram em algumas dessas situações e se mostraram interessados em ler mais sobre.

Propomos que se busque, em outros materiais, atividades que contenham as histórias e as lutas dessas pessoas para que se trabalhem informações que apareçam, por exemplo, as preposições de tempo e de espaço, o tempo presente dos verbos, o verbo modal 'should', para citar alguns. Ademais, outra atividade que pode ser feita é a utilização de vídeos disponibilizados no Youtube contendo o discurso de alguns deles, e ainda vídeos ${ }^{9}$

\footnotetext{
${ }^{9}$ Cota não é esmola. Canção de Bia Ferreira. Disponível em: 〈https://www.youtube.com/watch?v=QcQIaoHajoM $>$. Acesso em: 03 set. 2018.
} 
outros (de música ou de humor) que abordem o tema para que a partir da multimodalidade, com a linguagem que os alunos já conhecem e com o uso de gêneros diversos, os alunos da EJA possam estabelecer relações que, em geral, não estão acostumados. Com isso, podemos gerar debates em torno do tema que se desenrolem na produção de textos reais em inglês (produção oral, produção escrita, tradução, compreensão oral e compreensão escrita). Nossa experiência com as atividades sugeridas nos revelou que elas se mostraram produtivas e localizadas, como nos incentiva o LC. Houve espaço de diálogo e de embates, sem a busca de um consenso ou de uma resposta verdadeira e única. Parece-nos que os alunos se sentem livres para expor suas opiniões no espaço da sala de aula.

Outra atividade que realizamos e que aqui propomos é a elaboração de práticas mais contextualizadas que, naquele tema, tragam o discurso dos ativistas para perto dos alunos. Para ilustrar, produzimos uma atividade chamada "A Curitiba/O Brasil que eu quero" (em língua inglesa) na qual os alunos deveriam pensar em soluções provisórias para sua cidade ou para seu país tendo em vista a conjuntura política e social em que se encontravam. Para isto, trabalhamos com a produção de cartazes em inglês, em dupla e com auxílio das professoras e de dicionários. Os alunos tinham de discutir entre si sobre o assunto e acordar em alguma proposta. Após a confecção do cartaz, eles o apresentaram em inglês para a turma. "I have a dream" (após trabalharmos com o discurso de Luther King, Jr.) foi ainda outra atividade construída em aulas posteriores com os alunos que resultou na escrita (em português e/ou em inglês) de diários que descreveram os sonhos daqueles alunos.

Para além desses ativistas mundialmente conhecidos, tratamos de levar jovens ativistas que estão mais próximas dos alunos de modo a desnaturalizar quem são essas pessoas e focar as atitudes que são bem-vindas a nossa sociedade. Para tanto, fizemos uso de textos em inglês sobre Sophie Cruz e sobre Malala de sítios ${ }^{10}$ da internet, modificados

Pena. Porta dos Fundos. Disponível em: 〈https://www.youtube.com/watch?v=NdIqyc-jSSs $>$. Acesso em: 03 set. 2018.

\footnotetext{
${ }^{10}$ Sobre Malala Yousafzai e Sophie Cruz: PIMENTEL, J., BERNUCCA, C., KHAL. Young activists who are changing the world. Disponível em: https://www.complex.com/life/young-activists-who-are-changing-theworld/. Acesso em: 27 set. 2018.
} 
por nós, para que eles trabalhassem seu entendimento e busca de informações, como serão exigidos em testes formais.

Trabalhamos ainda com reading strategies para que a leitura daqueles textos biográficos não tomasse todo o tempo da aula apoiado em traduções, como acontece rotineiramente, e também para que os alunos aumentassem seu repertório e desenvolvessem habilidades estratégicas para atuar em outros espaços. Por mais que o livro didático não abordasse este conteúdo, foi o que nos pareceu mais plausível e de necessidade daqueles alunos naquele contexto. Para finalizar o tema, trabalhamos com a música "Stand by me", de autoria de Ben E. King em três versões, adentramos no tempo futuro por ser recorrente no discurso "I have a dream" e na música e falamos sobre os nossos sonhos em forma de um diário. Essas atividades somente foram possíveis com a ajuda de dicionários, internet, projetor e, principalmente, colaboração entre professoras e alunos.

Sobre esse tipo de atividade e tratando deste tema, os alunos demonstraram perceptível engajamento. Parece-nos que tratava de assuntos sobre os quais desconheciam formalmente (por exemplo, os direitos assegurados pela constituição e os declarados pelos direitos humanos) e que tinham necessidade de recorrer (direito à moradia, ao trabalho e ao respeito, independentemente de sua classe, cor e gênero). Outra atitude que nos chamou a atenção foi sua mudança de posição quanto à luta por direitos que, para eles, parecia ser travada somente por alguns, e quando viram pessoas contemporâneas, jovens e as causas

pelas quais lutavam, perceberam que em seu dia a dia também poderiam fazer algo, que, mesmo em uma dimensão local, já era o diferencial que desejavam.

Certamente, o trabalho empreendido tornou-se possível em virtude da flexibilidade do planejamento das professoras e da tentativa de tornar o currículo mais significativo e real, bem como de sua disposição para procurar textos em diversas fontes e atividades que fossem de interesse dos alunos e para escutar os alunos e o que tinham a dizer. Sobre isso, muitos foram os relatos contando as situações pelas quais passaram e que auxiliaram na construção de saberes e atitudes outras com relação às más experiências e também às experiências exitosas dos estudantes.

\section{Considerações finais}


Ao longo do texto, demonstramos nossa afinidade com a perspectiva de LC redefinida de viés pós-estruturalista por entendermos que ela percebe os sujeitos aluno e professor como fazendo parte de contextos mais amplos, que extrapolam a sala de aula. Ademais, leva em consideração a leitura como um processo interpretativo contínuo, um eterno becoming, que acontece a partir de um olhar não-inocente sobre si, sobre o outro, sobre o texto e sobre o mundo. Portanto, é um olhar que compreende a contingencialidade dos espaços enunciativos (FOGAÇA et al, 2017) e é constitutivamente reflexivo, que suspeita de si e se percebe enquanto construção. Assim, mais do que refletir sobre sua prática levando em conta o contexto institucional, o professor crítico pode agir de modo a considerar o aluno enquanto agente, e colaborativamente, construir conhecimentos passíveis de serem rasurados e reestruturados. Pode utilizar seu espaço de aula para aprender a aprender e ajudar os alunos a empreenderem atitudes investigativas. Ainda, pode fomentar no aluno o entendimento de que há muitas possibilidades e verdades para além das que são apresentadas pelos livros didáticos e de que ele é também o responsável pelas suas interpretações.

Entendemos que nossa atitude em relação ao livro didático foi produtiva porque o tomou enquanto um dos materiais que deve estar disponível ao professor e ao aluno. Destacamos que há outros livros, mais e menos recentes, que utilizamos para pensar nas atividades que os alunos nos perguntam e parecem desconhecer. Há professores de história, de geografia, de outras disciplinas a quem podemos recorrer caso tenhamos alguma dúvida ou queiramos sugestões para tratar certos temas. Ademais, este material foi localizado a partir do tempo e do espaço nos quais os alunos habitam, o que coloca em relevo a agência das professoras e a leitura do seu contexto de trabalho.

Tentamos, em nossa prática, responder a esses anseios, sejam eles de viés mais estruturalista e tradicional ou não, porque entendemos a sala de aula enquanto um espaço de construção que nunca tem fim. A voz e a agência do aluno se fazem tão importantes quanto a do professor e ambos devem trabalhar colaborativamente para a produção de significação, para a leitura de si e do mundo do qual fazem parte.

Finalmente, retomando o livro didático e já levando em consideração sua adoção muitas vezes obrigatória nas salas de aula, corroboramos Menezes de Souza (2011b) 
quando sugere que haja o poder de decisão do professor quando da escolha das atividades (e até mesmo da ordem de execução das mesmas), pois ele mais do que ninguém conhece o contexto dos seus alunos, seus interesses e o que pode ser trabalhado produtivamente naquele contexto/dia específico.

\section{Agradecimento}

Agradecemos à Coordenação de Aperfeiçoamento de Pessoal de Nível Superior (CAPES) pela concessão de bolsa de estudos no doutorado.

\section{REFERÊNCIAS}

AARÃO, S. A.; ZATTI, P. Caminhar e transformar: língua estrangeira moderna (inglês e espanhol). São Paulo: FDT, 2013, p. 98-130.

ALLWRIGHT, R. L. What do we want teaching materials for? ELT Journal, v. 36, n. 1, 1981.

ARAÚJO, R. G.; AMORIM, A.; DANTAS, T. R. A comunidade vai à escola da EJA: fazer o quê? Revista EJA em debate, v. 5, n. 8, 2016.

BOHN, H. I. Ensino e aprendizagem de línguas: os atores da sala de aula e a necessidade de rupturas. In: MOITA LOPES, L. P. (Org.). In: BON, H. I. (Org.) Linguística aplicada na modernidade recente: Festschrift para Antonieta Celani. São Paulo: Parábola, 2013, p. 1537.

BRASIL. LDB: Lei das Diretrizes e Bases da Educação Nacional - Lei nº 9394/96, de 20 de dezembro de 1996 que estabelece as diretrizes e bases da educação nacional. 5. ed. Brasília: Câmara dos deputados, Coordenação Edições Câmara, 2010.

CORACINI, M. J. O processo de legitimação do livro didático na escola de ensino fundamental e médio: uma questão de ética. In: CORACINI, M. J. (org.). Interpretação, autoria e legitimação do livro didático. São Paulo: Pontes, 1999. p. 33-43.

CRAWFORD, J. The role of materials in language classroom: finding the balance. In: RICHARDS, J. C., RENANDYA, W. A. (eds.) Methodology in language teaching. Cambridge: Cambridge University Press, 2002, p. 80-92. 
CUNNINGSWORTH, A. Choosing your coursebook. Oxford: Heineman, 1995.

DELEUZE, G.; GUATTARI, F. Mil platôs: capitalismo e esquizofrenia. Tradução de Aurélio Guerra Neto e Célia Pinto Costa. Rio de Janeiro: Ed. 34, 1995.

DUBOC, A. P. M.; FERRAZ, D. M. Reading ourselves: placing critical literacies in contemporary language education. Revista Brasileira de Linguística Aplicada, v. 18, n. 2, p. 227-254, 2018.

EJA moderna: Educação de jovens e adultos. Organizadora Editora Moderna. Editora responsável: Virgínia Aoki. São Paulo: Moderna, 2013.

FOGAÇA, F. C.; HIBARINO, D.; KLUGE, D.; JORDÃO, C. M. Entrevista com Clarissa Jordão. Revista X, v. 12, n. 1, p. 187-194, 2017.

FREITAS, M. L. Q.; RIBEIRO, N. N. A. Pesquisa colaborativa: a (per)feição de uma nova pesquisa na educação de jovens e adultos e a implicação dos sujeitos. Arquivos analíticos de políticas educativas, vol. 22, n. 64, p. 1-20, jun., 2014.

HOLDEN, S.; ROGERS, M. O ensino da língua inglesa. 2. ed. São Paulo: SBS, 2002.

HUTCHINGSON, T.; TORRES, E. The textbook as agent of change. ELT Journal, v. 48, n. 4, 1994.

JORDÃO, C. M. A. Abordagem comunicativa, pedagogia crítica e letramento crítico farinhas do mesmo saco? In: HILSDORF ROCHA, C.; MACIEL, R. F. (Orgs.). Língua estrangeira e formação cidadã: por entre discursos e práticas. Campinas, SP: Pontes, 2013a, p. 69-90.

JORDÃO, C. M. A posição do professor de inglês no Brasil: hibridismo, identidade e agência. Revista Letras \& Letras, v. 26, n. 2, p. 427 - 442, jul-dez. 2010.

JORDÃO, C. M. A. Aprendendo língua estrangeira com o professor Jacotot: criticidade na pedagogia crítica e no letramento crítico. In: MATEUS, E.; BUENO, N. (Orgs.) Estudos críticos da linguagem e formação de professores/as e línguas: contribuições teóricometodológicas. São Paulo: Pontes, 2014, p. 1-13.

JORDÃO, C. M. A. Letramento crítico em 2.500 palavras, mais ou menos... In: JORDÃO et al (Orgs). PIBID-UFPR nas aulas de inglês: divisor de águas e formador de marés. Campinas, SP: Pontes, 2013b, p. 41-46. 
KUMARAVADIVELU, B. Individual identity, cultural globalization, and teaching English as an international language: the case for an epistemic break. In: ALSAGOFF, L. et al. (Editors) Principles and practices for teaching English as an international language. New York: Routledge, 2012, p. 9-27.

LEFFA, V. J. Produção de materiais de ensino: teoria e prática. Pelotas: Educat, 2003.

MENEZES DE SOUZA, L. M. T. Para uma redefinição de letramento crítico: conflito e produção de significação. In: MACIEL, R. F.; ARAUJO, V. A. (Orgs.) Formação de professores de línguas: ampliando perspectivas. Jundiaí: Paco Editorial, 2011a, p. 128-140.

. O professor de inglês e os letramentos no século XXI: métodos ou ética? In: JORDÃO, C. M.; MARTINEZ, J. Z.; HALU, R. C. (Orgs.) Formação “desformatada”: práticas com professores de língua inglesa. Campinas: Pontes, 2011b, p. 279-303.

MILLER, I. K. Formação de professores de línguas: da eficiência à reflexão crítica e ética. In: MOITA LOPES, L. P. (Org.) Linguística aplicada na modernidade recente: Festschrift para Antonieta Celani. São Paulo: Parábola, 2013, p. 99-121.

PARANÁ. Secretaria de Estado da Educação. Diretrizes curriculares da educação de jovens e adultos no estado do Paraná. Curitiba: SEDD, PR, 2006.

PENNYCOOK, A. Critical moments in a TESOL praxicum. In: NORTON, B.; TOOHEY, K. (Eds). Critical Pedagogies and language learning. Cambridge: Cambridge University Press, 2004, p. 327-343.

SALAS, M. R. English teachers as materials developers. Actualidades Investigativas en Educacion. San José, vol. 4, n. 2, p. 1-17, jul./dez. 2004.

SILVA, D. J. A. Os adultos e a aprendizagem do inglês: uma análise da relação de estudantes da educação de jovens e adultos com uma língua estrangeira. 2011. 137 f. Dissertação (Mestrado em Letras) - Departamento de Ciências Humanas, Letras e Artes, Universidade Federal do Paraná, Curitiba, 2011.

TICKS, L. K.; SILVA, E. A.; BRUM, M. H. A pesquisa colaborativa socialmente situada no contexto escolar: processos dialógicos possíveis. Linguagem em (Dis)curso, Tubarão, SC, v. 13, n. 1, p.117-156, jan./abr. 2013. 
VILAÇA, M. L. C. O Material Didático no Ensino de Língua Estrangeira: definições, modalidades e papéis. Revista Eletrônica do Instituto de Humanidades. v. 8, n. 30, p. 1-14, jul./set. 2009. 